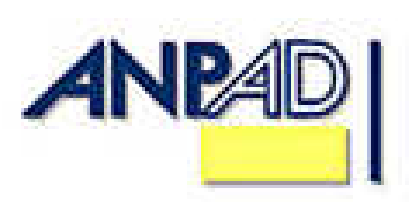

Available online at

http://www.anpad.org.br/bar

\title{
Sales Managers' Performance and Social Capital: the Impact of an Advice Network
}

\author{
Danny Pimentel Claro * \\ E-mail address: danny@insper.org.br \\ Insper Instituto de Ensino e Pesquisa \\ São Paulo, SP, Brazil.
}

Sílvio Abrahão Laban Neto

E-mail address: silvioaln@insper.org.br Insper Instituto de Ensino e Pesquisa São Paulo, SP, Brazil.

\begin{abstract}
The aim of this study is to research a sales manager's social network and demonstrate that sales managers who are central in closure structures of an advice network achieve high sales performance. Considering the results obtained and the discussion provided in the hypotheses presentation, we argue that sales managers must have accurate perceptions of their network. Two different networks were analyzed: friendship and advice; and we also considered two different views of network structure that claim to make an impact on performance and, to explore this claim, we examined whether sales managers, in order to improve sales performance, develop either a highly cohesive network or one containing structural holes. Census data was collected from over 500 personnel of an agricultural input retailer with 23 divisions. Estimates from a sample of 101 sales managers demonstrated, in the advice network, how important a highly cohesive structure is to a sales manager's performance. These results suggest that firms should encourage contacts among their personnel to disseminate and share technical and commercial information. By stimulating cohesive structures of contacts for the purpose of receiving advice, firms create an environment for sales managers to develop relationships of trust in which social norms prevail.
\end{abstract}

Key words: networks; social capital; sales performance; relationship marketing.

Received 10 September 2008; received in revised form 01 April 2009.

Copyright (C) 2009 Brazilian Administration Review. All rights reserved, including rights for translation. Parts of this work may be quoted without prior knowledge on the condition that the source is identified.

\footnotetext{
* Corresponding author: Danny Pimentel Claro

Insper Instituto de Ensino e Pesquisa, Rua Quatá, 300, Vila Olímpia, São Paulo, SP, 04546-042, Brazil.
} 


\section{INTRODUCTION}

A rich body of work from the cognitive sales research tradition demonstrates the relationship between knowledge structure and sales performance (Weitz, Sujan, \& Sujan, 1986). For example, research indicates that more effective salespeople have richer and more interrelated knowledge structures concerning their customers (Sujan, Sujan, \& Bettman, 1988), rely on more distinctive selling scripts (Leigh \& McGraw, 1989; Leong, Bush, \& Roedder, 1989; Matsuo \& Kasumi, 2002), organize and weigh the category attributes of a sale situation differently (Szymanski \& Churchill, 1990), possess more categories in memory (Sharma, Levy, \& Kumar, 2000) than less effective salespeople, and create information-search networks to gain access to critical information about customers (Gonzalez, Kapelianis, Walker, \& Hutt, 2007).

While providing valuable insights into sales performance, recent trends in theory and practice highlight an important gap in the socio-cognitive sales paradigm. No studies, to our knowledge, have examined the salesperson's (hereafter referred to as the sales manager) network structure and the purpose of maintaining such a network of contacts. There is a diverging view of network structure in the literature. Coleman (1988) argues that having a network of a certain configuration (e.g. highly cohesive wherein all the actors are closely connected) allows for the effective exchange of information. Burt (1992) argues a more strategic perspective, in which actors can gain informational benefits of access, timings and flows when their contacts do not know each other. Both views argue about how the structure of the firm affects members in the network. While Coleman (1988) states that everyone in the network benefits, Burt (1992) states that certain actors will benefit more (in certain ways) than others.

These diverging views invite further work attempting to theoretically and empirically examine whether a sales manager develops a network combining high cohesiveness (i.e. Coleman's view of the network structure) and structural holes (i.e. Burt's view of the network structure) to achieve high sales, or either one separately. There is certainly no consensus as to exactly which network structure impacts sales performance. There is little agreement on the proper use of this centrality position in the network and also in which kind of network it is important to be embedded.

Recent literature stresses the importance of identifying not only the structure of a social network, but also the purpose of forming a network (Cross \& Prusak, 2002; Krackhardt, 1998). In this article, we consider two types of network that are based on its purpose: friendship and advice networks. The friendship network refers to a free set of relationships of affective and social bonds. The advice network addresses who goes to whom for work-related or technical advice.

The aim of our article is to investigate the type and structure of a sales manager network and its influence on sales performance. We developed two hypotheses to study the issue of networks and sales performance. Empirical census data was collected from over 500 personnel of an agricultural input retailer with 23 divisions. We mapped the sales managers' networks: their friendship network contains 1,284 ties and the advice network 774 ties. To test our hypotheses, regression models were estimated considering the sample of 101 sales managers.

The concept of the type of network and network structure will be explored in the following two sections. First, we shall take up the friendship and advice purpose of networks and then examine the centrality concept as it refers to the locations of positions within the network structure. In the third section, the hypotheses are developed on the basis of previous literature of network and sales force. The methodology is presented in the fourth section, followed by the results. At the end, we present a discussion and conclusions. 


\section{SOCIAl CAPITAL: FriendSHIP AND AdVICE Network}

Built on Coleman's (1988) discussion of social capital, Burt (2007b) defines such capital by its function. According to these two highly regarded authors, social capital is not a single entity but a variety of different entities having two characteristics in common: they all consist of some aspect of social structure, and they facilitate certain actions of individuals who are within the structure. Like other forms of capital, social capital is productive, enabling the achievement of certain goals that would not be attainable without it. It consists of a social structure formed by persons or corporate actors. Unlike other forms of capital, social capital is inherent to the structure of relations between actors and among actors.

In sociological terms, each actor has control over certain resources (i.e. information) and interests in certain resources and events, and therefore social capital constitutes a particular kind of resource available to an actor. The concept of social capital allows actors to take information and show how it can be combined with other resources to produce different system-level behavior or, in other cases, different outcomes for individuals. Information is essential in any business setting and provides the basis for action in the social structure. Information can be expected to spread across the people in a market, but it will circulate within groups before it circulates between groups. However, acquisition of information is costly. At a minimum, it requires attention, which is always in scarce supply. One means by which information can be acquired is by use of social relations that are maintained for different purposes (Burt, 1980, 1992, 2007a, 2007b; Coleman, 1988).

Network relationships may be assessed as a multidimensional concept. One critical issue is what type of network relations enables sales manager to increase net sales, i.e., sales performance? A network composed of incidental communication links, such as a mechanical How do you do? may not be as rich in relevant information as a network composed of critical advice relationships (Burt, 1980). It is not surprising when you meet a person at an event and find out that you have a mutual friend in common. In the literature, the term small world is often associated with the tendency that people at different geographic locations are connected through a few intermediaries. Granovetter (1973) showed that weak ties are actually the matter of intermediaries. Watts (2004) and Barabasi (2003) showed how close someone is from the point that they might return to their own ego-network.

The cognitive social structure considers two main different types of networks. First, the advice network represents the instrumental, workflow-based network in the organization (Krackhardt, 1990). Basically, it addresses who goes to whom for work-related or technical advice (Cross \& Prusak, 2002). Second, the network assessed was the friendship network. This is a free set network. It is not necessarily linked to the routine work done in the organization, but it does capture important affective and social bonds that can affect trust, especially in times of change (Krackhardt \& Stern, 1988). After discussing friendship and advice networks and their relation with social capital, in this section we will discuss elements of network structure: closure and structural holes.

\section{Network Structure: Closure AND Structural Holes}

Closure and structural holes have been the foundation for studies on networks (Burt, 1992, 2007b; Coleman, 1988). These two mechanisms do not assume that networks replace information so much as they affect the flow of information and what people can do with it. Both mechanisms begin with the assumption that communication takes time, so prior relationships affect who knows what. Even though the two mechanisms share the same assumption, they are singular.

In closure, it can be said that people are always doing things for each other. Closure depends on two elements: trustworthiness of the social environment - which means that obligations will be repaid - 
and the actual extent of social norms (Coleman, 1988). Social norms arise as attempts to limit negative external effects or encourage positive ones. In some cases, the norms are internalized through peoples' social principles and values. In others, they are largely supported through external rewards for selfless actions and disapproval for selfish actions. Nevertheless, whether supported by internal and/or external sanctions, norms of this sort are important in overcoming the opportunistic behavior in collective action. Norms are intentionally established as a means of reducing negative externalities, and their benefits are captured by those who are responsible for establishing them. Nevertheless, the capability of establishing and maintaining norms depends on some properties of the closure structure affected by one actor's action over which another actor has no control.

Closure of the social structure is important not only for the existence of effective norms but also for another form of benefit: the trustworthiness of social structures that allows the proliferation of obligations and expectations. Defection from an obligation is a form of imposing one negative externality on another. Reputation arises in closure, and collective sanctions ensure trustworthiness. Closure may then be understood as a group within which there is extensive trust, and social norms create a positive environment for bonding.

Recent literature suggests the use of degree centrality to capture closure (Krackhardt, 1990). Degree centrality refers to the maximum possible degree that falls on the geodesics (i.e. the shortest path between points in space) between the largest possible number of other points and, since it is located at the minimum distance from all other points, it is maximally close to them (Freeman, 1979). We can expect from this definition that the degree is associated with the potential activity in communication of people in the network. It is reasonable to assume that a person who is in a position that permits direct contact with many others should begin to see himself and be seen by those others as a major channel of information. At least with respect to the others with whom he is in contact, he is a focal point of communication. He is likely to develop a sense of being in the mainstream of the information flow in the network (Burt, 2007b). A person in such a position can influence the group by withholding or distorting information in transmission.

Structural holes are the gaps in the structure of the information flow between clusters of connected people. A structural hole between two groups means that some people are unaware of other people. This happens because people are focused on their own activities and forget to look at others. The argument that underlies structural holes is the participation in and control of the process of information sharing. There is therefore a brokerage opportunity. Several authors have shown the importance of such a brokerage opportunity. We find evidence in the work of Granovetter (1973) on the strength of weak ties, Freeman (1977) on betweenness centrality, Cook and Emerson (1978) on the benefits of having exclusive exchange partners and Burt (1980) on the structural autonomy created by complex networks. They all agree that structural holes create a competitive advantage for an individual whose relationships span the holes.

Structural holes separate non-redundant sources of information, sources that are more additive than overlapping. There is also the potential for control advantage. The holes between a broker's contacts mean that he can broker communication while displaying different beliefs and identities to each contact. As closure, a structural hole is often addressed in literature by the concept of centrality. There is a common sense that betweenness centrality is an important structural attribute of social networks (e.g. Burt, 2007a; Cross \& Prusak, 2002). Figure 1 summarizes the important issues that differentiate the network structures considering the social context within which social networks develop as well as some static (information value, control, position, ties) and dynamic aspects (ties' characteristics that develop overtime). 
Figure 1: Issues on Network Structure

\begin{tabular}{|c|c|}
\hline Brokerage as Social Capital & Closure as Social Capital \\
\hline \multicolumn{2}{|l|}{ Static } \\
\hline Value of non-redundant information & Value of redundant information \\
\hline $\begin{array}{l}\text { Control through regulating the flow of } \\
\text { information }\end{array}$ & $\begin{array}{l}\text { Control through sanctioning and amplification } \\
\text { of existing opinion }\end{array}$ \\
\hline Center in a star-shaped structure & Dense local structure \\
\hline 'Strength of weak ties' & 'Strength of strong ties' \\
\hline \multicolumn{2}{|l|}{ Dynamic } \\
\hline $\begin{array}{l}\text { Striving for non-redundant ties, brokerage } \\
\text { positions, and open triads }\end{array}$ & Striving for redundant ties and closed triads \\
\hline Preferring ties with unconnected alters & Preferring ties with connected alters \\
\hline \multicolumn{2}{|l|}{ Social Context } \\
\hline Competitive and entrepreneurial settings & Cooperative and collaborative settings \\
\hline Acquisition of private goods & Production of collective goods \\
\hline
\end{tabular}

Figure 2 presents a simplification of a social network. Imagine a sales manager D connected to several individuals who are connected with each other. The sales manager D holds the higher score for degree centrality. On the other hand you have another sales manager $\mathrm{H}$ who is the only linkage between one side and the other of the network. In this case, $\mathrm{H}$ has the highest betweenness centrality.

Figure 2: Degree and Betweenness Centrality

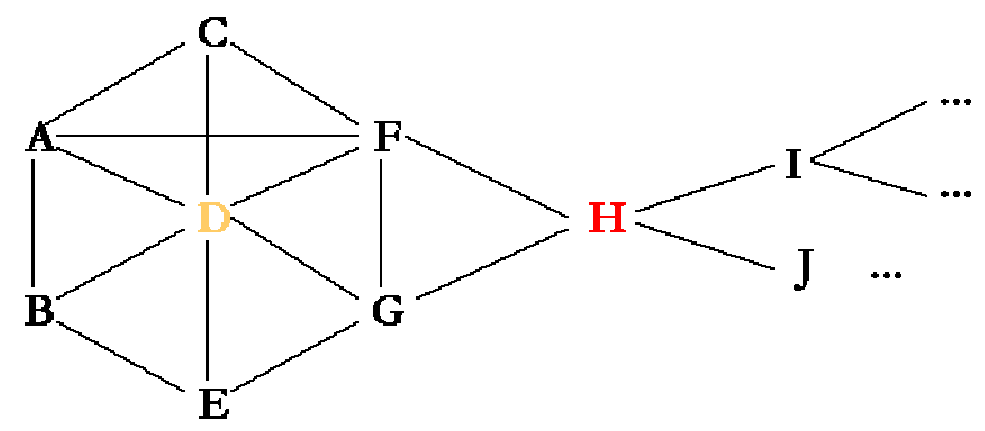

The review of the relevant literature performed in the previous sections will guide our hypotheses development and verification to be carried out in the next two sections.

\section{HYPOTHESES}

The literature review allows us to present four hypotheses about sales managers' social networks and sales performance encompassing network types and structural elements and their relation with sales performance. In sales performance literature, annual sales and the growth of sales over time is the central outcome expected by companies (Jones, Brown, Zoltners, \& Weitz, 2005; Plouffe \& Barclay, 2007). Following this literature, we consider sales performance by means of these two central outcomes. 
When a sales manager asks a contact for information, thus incurring an obligation, he does so because the information may help him in addressing some needs and/or capture some benefit (Weitz et al., 1986). For instance, the information may be critical in order to close a deal with a client. The manager does not consider that it does the other a benefit, instead he adds to a fund of social capital that will be available in a time of need. This strengthens the relationship between the two actors by creating an environment for exchange of information - or favors. Similarly, trustworthiness is a source of social capital. A sales manager's trustworthiness will facilitate others' actions. A sales manager who serves as a source of information for another individual does so because he is well informed for his own benefit not for the others who make use of such information. In addition, ties with many actors are important for a salesperson's ability to influence others to share knowledge (Bulte \& Wuyts, 2007). By means of this fluid flow of information, we expect that the sales manager will increase his sales.

As sales managers are concerned about their own sales, it is expected that advice information is prioritized. These managers have been overloaded with bureaucratic work about customer profiles, sales reports, expenses reports, and activities reports (Weitz \& Bradford, 1999). As time has become scarce for these managers, they will attempt to focus on the work related information. In addition, sales managers tend to be physically separate, which requires certain resources to keep the contacts. Resources like the telephone and email are used to complement face-to-face contacts with others. Considering these thoughts, we hypothesize that:

H1a: A sales manager with a closure structure (i.e. high degree centrality) in an advice network achieves high sales performance.

A complementary hypothesis to degree centrality refers to the type of network. Degree centrality in friendship networks is expected to be more important than in the advice network. Managers may have access to valuable information in his or her group of close friends (Krackhardt \& Hanson, 1993). The information in theses structures may allow for cross-checking among other members of his tied cluster of friends. The reliability of the information and the details can be easily checked. Therefore, we hypothesize that:

H1b: A sales manager with a closure structure (i.e. high degree centrality) friendship network achieves high sales performance.

Sales managers connected across a structural hole explore the benefits of betweenness centrality. They have broader access to information because of their diverse contacts. While degree centrality is viewed in terms of the number of direct contacts, it is also likely that salesperson networks pay off most effectively through contacts outside a dense structure (Üstüner \& Godes, 2006). This means they are more often aware of new opportunities and aware earlier than their close contacts. Betweenness centrality allows sales managers to get timely access to information from other divisions or the headquarters. Sales managers are also likely to be considered as potential candidates for inclusion in new opportunities (Burt, 1992). They also have control over some benefits. Sales managers central in structural holes are likely to have sharpened and displayed their capabilities because they have more control over the substance of their work defined by the relationships with subordinates, superiors and colleagues (Cross \& Prusac, 2002). These benefits strengthen one another at any moment in time and accumulate over time.

As sales managers need complex technical and commercial information, one might suggest that they will focus on the advice network. In order to offer value to customers, the managers will create bridges between clusters separated by the holes. Information about work is critical, and sales managers will seek it to achieve higher performance. Therefore, we expect that:

H2a: A sales manager in a brokerage position (i.e. betweenness centrality) in an advice network achieves high sales performance

One might also suggest that the brokerage position will be better explored when you are among friends. The costs of controlling information may be lower in friendship networks (Krackhardt \& 
Hanson, 1993). Sales managers will use their friends to explore the benefits of brokerage. Considering the friendship network, we hypothesize that:

H2b: Sales managers in a brokerage position (i.e. betweenness centrality) in a friendship network achieve high sales performance

In addition to the social network variables, we can intuitively expect that other factors may impact performance. The age of a sales manager might influence his performance positively. One might suggest that with age a manager gains experience and becomes better prepared for the challenges of selling. Years with the firm can impact performance for the same reasons as age and additionally managers more familiar with the firm's procedures tend to learn and use more efficient ways to deal with the system. The education level is also expected to have a positive impact on performance. Managers are required to engage in before and after sales activities. Most of the activities are related to technical complex methods related to the products. Another factor that one might consider is team effect. As managers may work closely together with other managers within one division, they are physically separated from the rest of the large sales group. Sales managers might be involved in large sales of the division or gain with the high spirit of sales within the division. Finally, we considered the effect of a sales manager that is located at the Office Headquarters. One might suggest that these sales managers are physically close to the high ranks in the formal hierarchy of a firm (e.g. president, vice presidents and directors). Important decisions are taken by these high-ranking people. We have not developed specific hypotheses for each of these six factors, though they are included in the model estimation. Before presenting the analysis and results of the hypotheses test, we describe, in the next section, the methodology used in this study.

\section{METHODOLOGY}

Census data was collected from over 500 personnel working for of a retailer of agricultural input products in Brazil. The mix of products contains chemicals, fertilizer, seeds, irrigation equipment, animal feed, veterinarian drugs and general farm accessories. The firm purchases products from major national and international brands to sell in its shops to producers of agricultural products (i.e. mainly soy, corn, coffee, sugar cane, dairy and cattle). The retailer has its own brands in several lines of products: animal feed, fertilizer and seeds. Overall the firm's net sales for 2007 totaled over 300 million dollars for about 1,100 clients. This retailer was selected because of the nature of the business, territorial coverage and number of sales people.

In this business, information is critical. Sales managers are always consulted for technical advice. They visit clients in order to identify specific needs and bundle an array of products for the whole cycle of the clients' products. There are 23 divisions with independent shops in each of the divisions. A typical shop has a manager in charge of operations and sales and 5-7 sales managers with internal (i.e. at the shop and by telephone) and external (i.e. visits to clients firms) activities. Each division has an infrastructure and inventory to conduct sales independently and competes with each other. There is a monthly meeting with division managers to evaluate results and provide updates on operational and strategic matters. The Commercial Director oversees the 23 divisions with the assistance of two Business Unit Managers (i.e. Animal Business and Agriculture Business). In total there are 148 sales people geographically spread over 4 states. Sales managers earn a fixed annual salary and bonus based on their own annual net sales and also on their division's annual net sales. Field sales managers have all expenses covered by the firm (e.g. car, telephone, hotel, meals).

Research measures. Two measures of performance were used. The measure of individual sales is computed (US\$) on the basis of the financial records from January through December of 2007. Sales Growth (US\$) represents the growth in sales over the past 3 years, 2005 through 2007. 
The four network measures are based on a combination of two types of network (i.e. advice and friendship) and two centrality measures (i.e. degree and betweenness). To identify an employee's advice network, the following questions were asked: Whom do you go to for help or advice at least once a week? Whom do you talk to when you miss a work-related meeting? Whom do you look for to gather information for an important project? To identify an employee's friendship network, the following questions were asked: Whom would you trust to confide your concerns about work-related issues? Whom would you invite for a happy hour after a work day? We considered the first ten names in order to guarantee the relevance of the contacts mentioned by the respondents. All names were entered in UCINET 6 to draw the network and estimate the two centrality metrics. To estimate degree centrality we followed the procedure of Borgatti, Everett and Freeman (2002), which considers the number of direct contacts to a given point in the network (i.e. number of persons) in a symmetric graph. This allows us to estimate the number of ties received by the given point in the network and the number of ties initiated by the given point. The degrees (in and out) thus consist of the sums of the values of the ties. The estimate is normalized by dividing by the maximum possible degree expressed as a percentage. The estimation of betweenness centrality also follows the procedure of Borgatti et al. (2002). Considering $b_{j k}$ as the proportion of all geodesics linking vertex $j$ and vertex $k$ which pass through vertex $i$. The betweenness of vertex $i$ is the sum of all $b_{j k}$ where $i, j$ and $k$ are distinct. Betweenness is therefore a measure of the number of times a vertex occurs on a geodesic. The normalized betweenness centrality is the betweenness divided by the maximum possible betweenness expressed as a percentage.

We included six control variables. The measure of age represents the number of years from the date of birth to the date of the data collection. The variable years with firm is the number of years since the first day at work in the firm. We also included a control variable for the education level considering the number of years the employee spent at school. This is a categorical variable ranging from illiterate (0) to graduate (8). The measure of team effect is the net sales of the individual minus the total sales of the division. There is a dummy variable for the kind of sales manager. We coded 1 for the sales people that are primarily in charge of field sales (i.e. visits to clients in loco), while 0 represents sales managers that mainly stay at the shop. Office Headquarters represents the sales people that make the sales or have an office at the firm's headquarters.

Correlation matrix and descriptive statistics are shown in Table 1. The correlations between the measures do not suggest problems of pairwise colinearity that would preclude the use of all constructs in the estimation. 
Table 1: Correlation Matrix and Descriptive Statistics

\begin{tabular}{|c|c|c|c|c|c|c|c|c|c|c|c|c|c|}
\hline & Mean & SD & Sales & $\begin{array}{c}\text { Sales } \\
\text { Growth }\end{array}$ & FD & AD & $\mathbf{A B}$ & FB & Age & Years & $\begin{array}{c}\text { Educat } \\
\text { level }\end{array}$ & $\begin{array}{l}\text { Team } \\
\text { Effect }\end{array}$ & $\begin{array}{l}\text { Field } \\
\text { Sales }\end{array}$ \\
\hline Individual Sales & 2.149 .249 & 2.954.209 & 1 & & & & & & & & & & \\
\hline Sales Growth & 853.875 & 1.325 .407 & $.73(* *)$ & 1 & & & & & & & & & \\
\hline FD $^{\mathbf{a}}$ & 9,40 & 3,78 & -.16 & -.11 & 1 & & & & & & & & \\
\hline $\mathbf{A D}^{\mathbf{a}}$ & 6,22 & 3,51 & .07 & .07 & $.54(* *)$ & 1 & & & & & & & \\
\hline $\mathbf{A B}^{\mathbf{a}}$ & 183,67 & 428,80 & -.05 & -.07 & $.32(* *)$ & $.58(* *)$ & 1 & & & & & & \\
\hline $\mathbf{F B}^{\mathrm{a}}$ & $1.439,54$ & $2.021,81$ & -.06 & -.02 & $.67(* *)$ & $.52(* *)$ & $.44(* *)$ & 1 & & & & & \\
\hline Age & 33,12 & 8,57 & $.40(* *)$ & $.29(* *)$ & -.19 & -.02 & -.13 & -.16 & 1 & & & & \\
\hline Years with firm & 5,18 & 3,41 & -.09 & -.22 & .11 & $.32(* *)$ & .02 & -.09 & $.29(* *)$ & 1 & & & \\
\hline Education level & 7,04 & 1,09 & $.28(* *)$ & $.23(*)$ & .08 & .01 & .08 & .15 & -.15 & $.40(* *)$ & 1 & & \\
\hline Team Effect & 14.380 .214 & 8.396 .867 & .01 & -.04 & $.34(* *)$ & $.27(* *)$ & $.25(*)$ & $.21(*)$ & -.13 & .01 & .16 & 1 & \\
\hline Field Sales & 0,40 & 0,49 & $.39(* *)$ & $.39(* *)$ & $-.25(*)$ & -.09 & .04 & -.09 & .12 & $.33(* *)$ & $.50(* *)$ & .04 & 1 \\
\hline Headquarter Based & 0,06 & 0,24 & .01 & .07 & $.21(*)$ & .15 & $.34(* *)$ & $.24(*)$ & .08 & -.02 & .03 & $.25(*)$ & .05 \\
\hline
\end{tabular}

a. FD: Degreee Centrality in a Friendship Network; AD: Degreee Centrality in an Advice Network; AB: Betweeness Centrality in an Advice Network; FB: Betweeness Centrality in a Friendship Network.

** Correlation is significant at the 0.01 level (2-tailed).

* Correlation is significant at the 0.05 level (2-tailed). 


\section{RESULTS}

We mapped 1,944 ties in the whole firm's advice network and 2,968 ties in the friendship network. The ego-network (i.e. contains only the people directly mentioned) of each sales manager was drawn. The sales managers' friendship network contains 1,284 ties and the advice network 774 ties. Figure 3 shows the advice network of the sales force. The advice network reveals the concentration of ties on the experts. People like business unit sales managers (\#23 and \#26), Commercial Director (\#62) and supporting staff (Logistics Manager \#295, Credit Manager \#15, IT Manager \#117 and Inventory Manager \#50) are at the center of the network. This shows the importance of commercial information and also shows the value of information from critical supporting positions within the network.

\section{Figure 3: Sales People Advice Network}

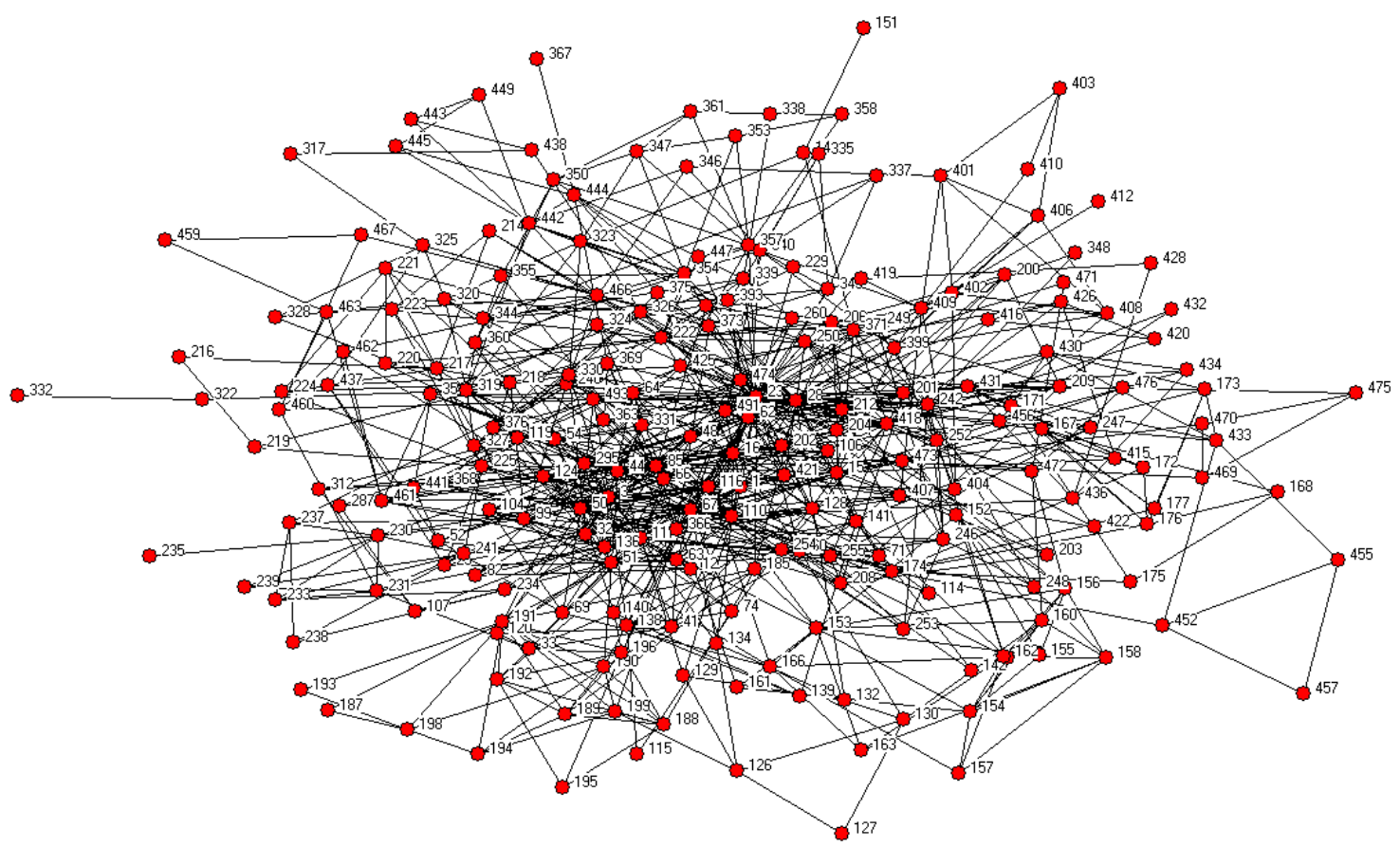

Figure 4 displays the friendship network, containing only the ego-networks of the sales people. It is possible to identify the divisions as small closed networks. Again the Business Unit Managers and the Commercial Director are at the center of the sales managers' network. However, the number of ties is relatively smaller than in the Advice Network shown in Figure 3. This shows that people tend to stick to people that are physically close. 


\section{Figure 4: Sales People Friendship Network}

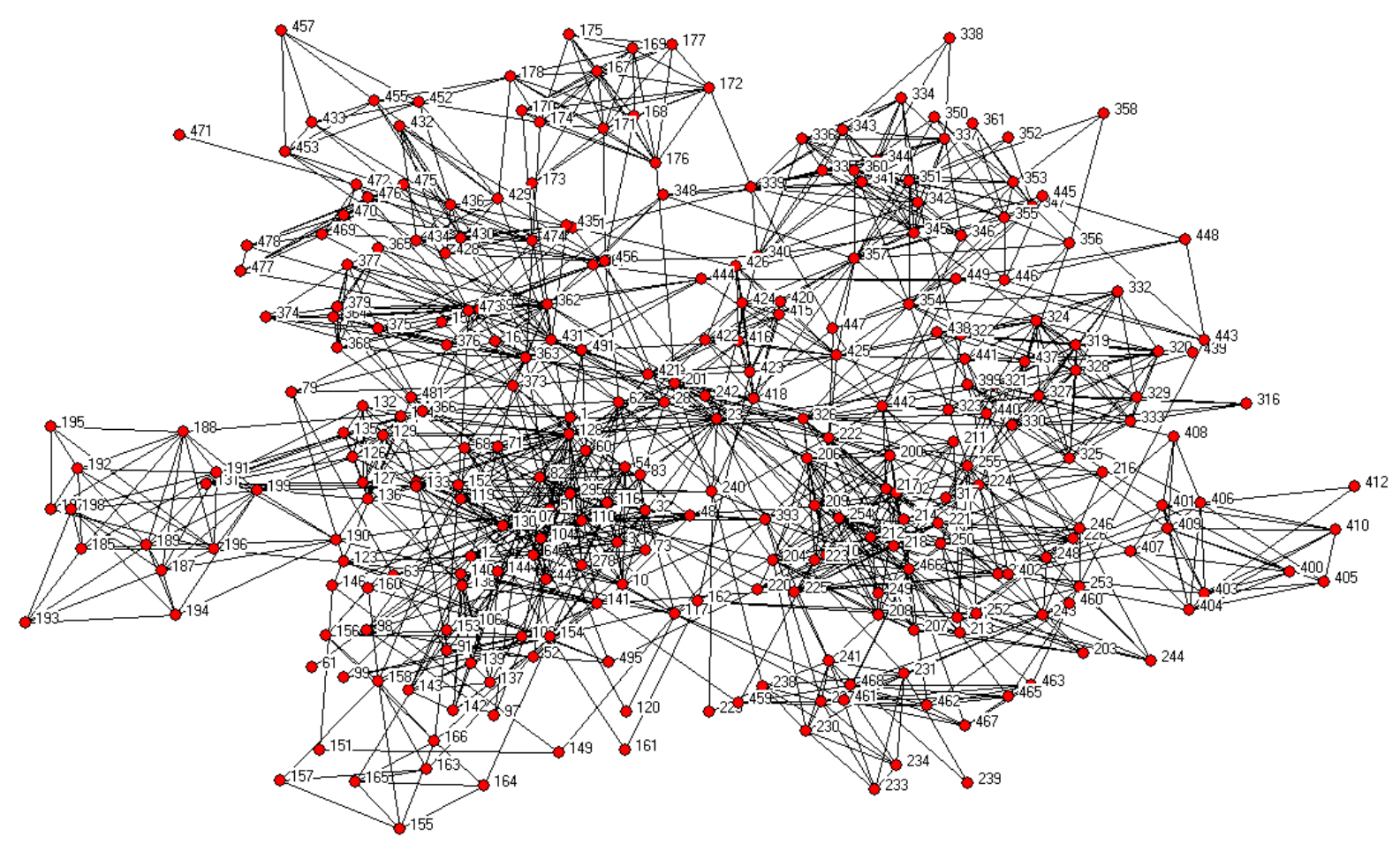

Table 2 summarizes the results of ordinary least square regression analysis. This table presents the standardized coefficients of the estimated regression model. The standardized coefficient allows comparison of coefficient size because all measures are in the same metric, namely standardized normal deviates. The equations were statistically significant below the .01 level in the F-test. The adjusted $\mathrm{R}^{2}$ for the significant equations are above .304 , which indicates that the results of the estimated model present a robust explanatory power. The explanatory power of the equations supports the examination of individual coefficients testing the effects of each individual variable.

Table 2: Results of the Regression Analysis

\begin{tabular}{|c|c|c|c|}
\hline & $\begin{array}{c}\text { Individual Sales } \\
\text { Model 1 }\end{array}$ & $\begin{array}{c}\text { Sales Growth } \\
\text { Model 2 }\end{array}$ & Hypothesis \\
\hline \multicolumn{5}{|c|}{ Degree Centrality } \\
\hline Advice Network & $\begin{array}{c}.37^{* *} \\
(2.71)\end{array}$ & $\begin{array}{c}.43^{* *} \\
(2.62)\end{array}$ & $\mathrm{H} 1 \mathrm{a}$ \\
\hline Friendship Network & -.18 & -.07 & $\mathrm{H} 1 \mathrm{~b}$ \\
& $(1.36)$ & $(.47)$ & $\mathrm{H} 2 \mathrm{a}$ \\
\hline \multicolumn{5}{|c|}{ Betweenness Centrality } \\
\hline Advice Network & -.14 & $-.25 \dagger$ & $\mathrm{H} 2 \mathrm{~b}$ \\
\hline Friendship Network & $(1.19)$ & $(1.73)$ & -.11 \\
& -.08 & $(.66)$ & \\
\hline
\end{tabular}


Table 2 (continued): Results of the Regression Analysis

\begin{tabular}{|c|c|c|c|}
\hline & $\begin{array}{c}\text { Individual Sales } \\
\text { Model } 1\end{array}$ & $\begin{array}{c}\text { Sales Growth } \\
\text { Model } 2\end{array}$ & Hypothesis \\
\hline \multicolumn{4}{|c|}{ Control Variables } \\
\hline Age & $\begin{array}{l}.41 * * \\
(4.23)\end{array}$ & $\begin{array}{c}.24 * \\
(2.07)\end{array}$ & \\
\hline Years with firm & $\begin{array}{l}-.18 \dagger \\
(1.65)\end{array}$ & $\begin{array}{l}-.23 \dagger \\
(1.78)\end{array}$ & \\
\hline Education level & $\begin{array}{l}.25^{* *} \\
(2.25)\end{array}$ & $\begin{array}{ll} & .12 \\
(.95) & \end{array}$ & \\
\hline Team Effect & $(.30)^{.03}$ & $(.47)^{-.05}$ & \\
\hline Field Sales & $(1.48)^{.16}$ & $(1.72)^{.22 \dagger}$ & \\
\hline Office at Headquarters & $(.14)^{-.01}$ & $(1,11)^{.13}$ & \\
\hline$\overline{\mathbf{R}^{2}}$ & $.386^{* *}$ & $.304 * *$ & \\
\hline$\overline{\Delta \mathbf{R}^{2}}$ & .313 & .20 & \\
\hline$\Delta \mathrm{F}$ & 5.287 & 2.88 & \\
\hline
\end{tabular}

$\dagger p<.10 ; * p<.05 ; * * p<.01$

$\mathrm{n}=101$. Regression coefficients are standardized coefficients $(\beta)$ and $\mid \mathrm{t}$-test| within parentheses.

We find significant support for hypothesis 1a. Sales managers with degree centrality in an advice network achieve high performance in terms of annual sales $(\beta=.37, p<.01)$ and sales growth $(\beta=.43$, $\mathrm{p}<.01)$. There is no significant impact of degree centrality in the sales manager's friendship network considering the performance measures $(\mathrm{H} 1 \mathrm{~b})$. There is a significant marginal negative impact of betweenness centrality in the advice network and the sales manager's sales growth $(\beta=-.25, \mathrm{p}<.10)$, as suggested by hypothesis 2 a. Sales managers in brokerage positions see a decrease in sales growth. This result may suggest that a sales manager invests time and effort to maintain his or her brokerage position that does not pay off in the long run. The results of the estimations show no significant impact of betweenness centrality in friendship network on the two measures of performance, as hypothesized $(\mathrm{H} 2 \mathrm{~b})$.

Several control variables have a significant effect on the performance of sales managers. Age appears to be associated with increasing sales. The older the sales manager is the higher the annual sales $(\beta=.41, \mathrm{p}<.01)$ and the higher the sales growth $(\beta=.24, \mathrm{p}<.05)$. Interestingly, the longer the period a sales manager is with the firm, the lower its performance $(\beta=-.18, p<.10 ; \beta=-.23, p<.10)$. In terms of education, the higher the level of education, the higher the annual sales $((\beta=.25, \mathrm{p}<.01)$. On the other hand, education does not significantly impact the long term measure of performance (i.e. growth rate). One might suggest that constant training and updating is necessary for sales managers. 


\section{CONCLUDING REMARKS}

The aim of our study was to research a sales manager's social network. While past studies in marketing have examined the direct effects of knowledge structure characteristics (Sujan et al., 1988; Szymanski \& Churchill, 1990) on performance, our findings show insights into the socio-cognitive perspective of sales management literature. In general terms, literature in the social network area puts forward the idea that the better your centrality in a network the better your outcomes. This is associated with the information benefits one might explore in terms of information control or being the first to access the information. People who do well are somehow better connected. The perspective we take in this paper follows the metaphor in which the social structure defines a kind of capital that can create for individuals or groups an advantage in pursuing their goals. Our study shows that sales managers central in closure structures of an advice network achieve high performance. The closure structure allows for sales managers to rely on social norms and trust. The closer the contacts are to each other, the better the performance in sales.

Considering the results of our study and the discussion provided in the hypotheses presentation, it appears to be important for sales managers to have accurate perceptions of their network. Without this, any evaluation of the costs and benefits of alternative response to customers based on the information obtained from the network can be misguided. More specifically, if managers either under- or overestimate the potential positive impact of the information obtained in their close group of advice contacts, their sales effort response cannot be properly set up. Firms can foster managers' initiatives toward improving relationships with other sales managers and staff personnel that may form their own advice network. This will allow them to access valuable information that supports their sales efforts. The mere process of gathering information from known ties and developing new ties of information may substantially enhance the chances of sales success.

The implications of our study are best viewed within the context of a practice oriented approach on the trends towards increasing customer knowledge and sales performance. Almost without exception, this approach tends to view customer relationships as a universally desirable idea - this is because some customer may not be as profitable as others. We advise managers to complement this approach with our hypotheses and results. Noteworthy is the basic postulate in our work that a sales manager may increase customer knowledge by setting up advice relationships with others. In the settings that we tested our hypotheses, sales managers have looked for new ways to satisfy customers. In this particular situation, there are enough advantages for sales managers to organize themselves to set up close advice network structures. In the absence of competitive advantages, the social networks do not have beneficial effects and, given the costs associated with maintaining the contacts within the network, are likely to be detrimental to performance. At the very least, our study should serve as a cautionary tale about the conditions that evoke the need to form network relationships. The value of a relationship is not defined within the relationship itself; it is defined by the social context around the relationship (Burt, 2007a).

In a future study, the relationship within a network could be investigated in terms of its intensity. Literature of strong and weak ties (Granovetter, 1973; Lin, 1988) can present interesting findings in a context of sales force. Future research should consider other concepts studied in social capital literature. For instance, network diversity may cause an impact on sales performance. Network diversity has been studied as the wide variety of contacts a sales manager may have: be it in the commercial department or in other departments (e.g. administrative, financial, IT, and logistics). 


\section{REFERENCES}

Barabasi, A. L. (2003). Linked: how everything is connected to everything else and what it means. New York: Plume.

Borgatti, S. P., Everett, M. G., \& Freeman, L. C. (2002). Ucinet 6 for windows. Harvard: Analytic Technologies.

Bulte, C. van den, \& Wuyts, S. (2007). Social networks in marketing, marketing science institute. Cambridge, MA: Marketing Science Institute.

Burt, R. S. (1980). Models of network structure. Annual Review of Sociology, 6(1), 79-141.

Burt, R. S. (1992). Structural holes: the social structure of competition. Cambridge: Oxford University Press.

Burt, R. S. (2007b). Brokerage and closure: an introduction to social capital. Cambridge: Oxford University Press.

Burt, R. S. (2007a). Secondhand brokerage: evidence on the importance of local structure for managers, bankers, and analysts. Academy of Management Journal, 50(1), 119-148.

Coleman, J. S. (1988). Social capital in the creation of human capital. American Journal of Sociology, 94(Supplement), S95-S120.

Cook, K. S., \& Emerson, R. M. (1978). Power, equity and commitment in exchange networks. American Sociological Review, 43(5), 721-739.

Cross, R., \& Prusac, L. (2002). The people who make organizations go or stop. Harvard Business Review, 80(6), 104-112.

Freeman, L. (1977). A set of measures of centrality based on betweenness. Sociometry, 40(1), 35-41.

Freeman, L. (1979). Centrality in social networks conceptual clarification. Social Networks, 1(3), 215-239.

Gonzalez, G., Kapelianis, D., Walker, B., \& Hutt, M. (2007, August). The sociocognitive determinants of account manager performance. Proceedings of the Annual Conference of the American Marketing Association, Washington, DC, USA.

Granovetter, M. S. (1973). The strength of weak ties. American Journal of Sociology, 78(6), 1360-1380.

Jones, E., Brown, S. P., Zoltners, A. A., \& Weitz, B. A. (2005). The changing environment of selling and sales management. Journal of Personal Selling \& Sales Management, 25(2), 105-111.

Krackhardt, D. (1990). Assessing the political landscape: structure, cognition, and power in organizations. Administrative Science Quarterly, 35(2), 342-369.

Krackhardt, D., \& Hanson, J. R. (1993). Informal networks: the company behind the chart. Harvard Business Review, 71(4), 104-111.

Krackhardt, D., \& Stern, R. (1988). Informal networks and organizational crises: an experimental simulation. Social Psychology Quarterly, 51(2), 123-140.

Leigh, T. W., \& McGraw, P. F. (1989). Mapping the procedural knowledge of industrial sales personnel. Journal of Marketing, 53, 16-33. 
Leong, S. M., Busch, P. S., \& Roedder, J. D. (1989). Knowledge bases and salesperson effectiveness: a script-theoretic analysis. Journal of Marketing Research, 26, 164-178.

Lin, N. (1988). Social resources and social mobility: a structural theory of status attainment. In R. Breiger (Ed.). Social mobility and social structure (Chap. 10, pp. 247-271). New York: Cambridge University Press.

Matsuo, M., \& Kusumi, T. (2002). Salesperson's procedural knowledge, experience, and performance: an empirical study in Japan. European Journal of Marketing, 36(7/8), 840-854.

Plouffe, C. R., \& Barclay, D. W. (2007). Salesperson navigation: the intraorganizational dimension of the sales role. Industrial Marketing Management, 36(4), 528-539.

Sharma, A., Levy, M., \& Kumar, A. (2000). Knowledge structures and retail sales performance: empirical examination. Journal of Retailing, 76(1), 53-69.

Sujan, H., Sujan, M., \& Bettman, J. R. (1988). Knowledge structure differences between more effective and less effective salespeople. Journal of Marketing Research, 25(1), 81-86.

Szymanski, D. M., \& Churchill, G. A. (1990). Client evaluation cues: a comparison of successful and unsuccessful salespeople. Journal of Marketing Research, 27, 163-174.

Üstuner, T., \& Godes, D. (2006), Better sales networks. Harvard Business Review, 84(7/8), 102-112.

Watts, D. (2004). Six degrees: the science of a connected age. New York: Norton \& Co.

Weitz, B. A., \& Bradford, K. D. (1999). Personal selling and sales management: a relationship marketing perspective. Journal of the Academy of Marketing Science, 27(2), 241-254.

Weitz, B. A., Sujan, H., \& Sujan, M. (1986). Knowledge, motivation, and adaptive-behavior: a framework for improving selling effectiveness. Journal of Marketing, 50, 174-191. 